\title{
Facile low power preparation and Hyperthermia studies of Maghemite nanoparticles synthesized by Sonochemical method
}

\author{
Sumangala T P ( $\square$ sumampoornima@gmail.com ) \\ Vellore Institute of Technology: VIT University \\ Janeesh George M \\ Vellore Institute of Technology: VIT University \\ Meera V \\ Vellore Institute of Technology: VIT University \\ Niroj Kumar Sahu \\ Vellore Institute of Technology: VIT University
}

\section{Research Article}

Keywords: Maghemite, Sonochemical method, Magnetic hyperthermia treatment, SAR value

Posted Date: February 21st, 2022

DOI: https://doi.org/10.21203/rs.3.rs-1360555/v1

License: (a) (i) This work is licensed under a Creative Commons Attribution 4.0 International License. Read Full License 
Title: Facile low power preparation and Hyperthermia studies of Maghemite nanoparticles synthesized by Sonochemical method

Authors: Janeesh George $\mathrm{M}^{\mathrm{a}}$, Meera $\mathrm{V}^{\mathrm{a} \#}$, N. K. Sahu ${ }^{\mathrm{b}}$, Sumangala T. $\mathrm{P}^{\mathrm{a}^{*}}$

Affiliation: ${ }^{\text {a }}$ Department of Physics, School of Advanced Sciences, Vellore Institute of

Technology, Vellore, Tamil Nadu- 632014, India

${ }^{\mathrm{b}}$ Centre of Nanotechnology, Vellore Institute of Technology, Vellore, Tamil Nadu - 632014,

India

Corresponding author*: Sumangala T P

Corresponding author email id: sumampoornima@gmail.com

Corresponding author phone number: +919892910175

\# Both authors contributed equally to the work

\begin{abstract}
Using inexpensive and nontoxic metal salt $\left(\mathrm{FeSO}_{4} \cdot 7 \mathrm{H}_{2} \mathrm{O}\right)$ as a reactant, $\gamma-\mathrm{Fe}_{2} \mathrm{O}_{3}$ (maghemite) nanoparticles with crystallite size around $80 \mathrm{~nm}$ have been synthesized in an aqueous medium by low power, low temperature and simple sonochemical method. XRD, Rietveld refinement and Williamson-Hall method was employed for understanding the structure of the synthesized sample. FTIR spectra were recorded for studying the presence of organics. MT measurement performed at 500 Oe showed that the sample exhibit a magnetization of about $34 \mathrm{emu} / \mathrm{g}$ at $300 \mathrm{~K}$ and hence can be used for magnetic hyperthermia treatment (MHT). Calorimetric studies performed showed an improvement in temperature up to $12{ }^{\circ} \mathrm{C}$ with a minimum time of 210 s. Specific absorption rate calculation showed that sample with minimum concentration is better for MHT.
\end{abstract}

Keywords: Maghemite; Sonochemical method; Magnetic hyperthermia treatment; SAR value 


\section{Introduction}

Magnetic particles have been the topic of research for many decades. After the advent of nanotechnology, there is a renewed interest in the study of magnetic nanoparticles (MNP). The most promising biomedical applications of these MNPs include Ferrofluids [1], bio-separation, hyperthermia treatment [2-5], magnetic resonance imaging (MRI) [6, 7], drug and gene delivery [8], manipulating cell membranes [9, 10], removing water pollutants [11]. Among the various applications, hyperthermia treatment is particularly useful for destroying cancer cells by localized heating and hence is technologically very important for humans. The use of Iron oxide nanoparticles for magnetic hyperthermia treatment of cancer was first demonstrated in 1957. The constraints imposed on MNPs for hyperthermia applications include superparamagnetic property which could be achieved by having particles in the size range of 20-30 nm. Another constraint for using in the biomedical application is the biocompatibility and non-toxicity of the MNPs.

Among the various MNPs, Maghemite $\left(\gamma-\mathrm{Fe}_{2} \mathrm{O}_{3}\right)$ a metal oxide is particularly interesting owing to their magnetic properties including relatively high magnetization, octahedral vacancies [12], non-toxicity, biocompatibility [13], and biodegradability [14-17]. Various synthesis protocols have been utilized for the synthesis of $\gamma-\mathrm{Fe}_{2} \mathrm{O}_{3}$ including Sol-gel combustion [8, 18], Micro-emulsion $[8,12]$, Solid-state reaction, Co-precipitation [19, 20], and Sonochemical method [21, 22].

In this work, we used a more effective sonochemical method for synthesis $\gamma-\mathrm{Fe}_{2} \mathrm{O}_{3}$. Sonochemical methods are preferable over other methods because it uses ultrasonic waves which results in acoustic cavitation. It can increase the reaction speed, reaction output, and energy usage is found to be more efficient. $\mathrm{Fe}^{2+}$ oxidizes to $\mathrm{Fe}^{3+}$ thus leading to maghemite $\left(\gamma-\mathrm{Fe}_{2} \mathrm{O}_{3}\right)$ [23]. Cavitation, expansion, and implosion produced by the Ultrasonication can cause oxidation, reduction, dissolution, decomposition, and hydrolysis. The free radicals of $\mathrm{H}^{+}$and $\mathrm{OH}^{-}$are generated by the Ultrasonic irradiation of aqueous liquids. The generated radicals can recombine

to form $\mathrm{H}_{2}$ and $\mathrm{H}_{2} \mathrm{O}_{2}$, and these resultant strong oxidants and reductants, in turn, are utilized during various sonochemical reactions in aqueous solutions. However, very high power of about $600 \mathrm{~W}$ is required in the formation of the maghemite phase [24, 25]. In this paper, we report the synthesis of maghemite by a very simple low power sonochemical method using bath sonicator instead of ultrasonic horn and its suitability for hyperthermia treatment. 


\section{Materials and Methodology}

\subsection{Synthesis of Nanoparticles}

The synthesis of maghemite was performed using a single precursor, $\mathrm{FeSO}_{4} \cdot 7 \mathrm{H}_{2} \mathrm{O} .0 .1 \mathrm{M}$ of the precursor was dissolved in $500 \mathrm{~mL}$ distilled water at room temperature using a magnetic stirrer (Remi, 5MLH, India) for $10 \mathrm{~min}$. The resultant solution was sonicated using an ultrasonic processor (PCi analytics ultra-bath sonicator, $120 \mathrm{~W}$, India) for $75 \mathrm{~min} .9 \mathrm{~mL}$ of $3 \mathrm{M} \mathrm{NaOH}$ solution was added after 15 min of starting ultrasonication. The solution changed color from dark green to black with the formation of maghemite nanoparticles. These nanoparticles were seen as a precipitate at the bottom. The supernatant was removed and the precipitate was washed several times with water and ethanol by removing the precipitate with a magnet. After washing, the precipitate was dried in a hot air oven at $120{ }^{\circ} \mathrm{C}$ overnight to remove any organics present. This powder was crushed and directly used without further heat treatment. Schematic representation of the synthesis procedure used and the possible mechanism of the nanoparticle is represented in Figure 1 (a) \& (b) respectively.
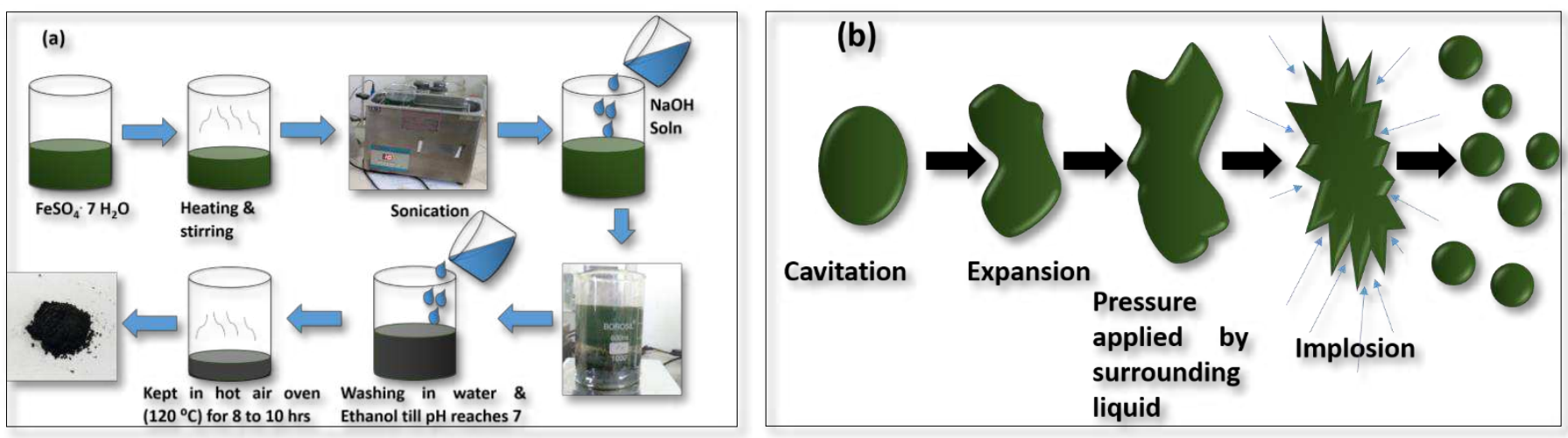

Figure 1: Schematic of (a) the synthesis procedure and (b) the mechanism of nanoparticle formation 


\subsection{Characterization}

The maghemite nanoparticles were analyzed by X-ray powder diffraction (XRD; Bruker's diffraction, $\mathrm{Cu}-\mathrm{k} \alpha$ radiation) in the $2 \theta$ range from $10^{\circ}$ to $90^{\circ}$ with $\lambda=1.5406 \AA$. The refinement of the X-ray diffraction pattern was done using Fullprof software. The full width at half maxima (FWHM) and the center position of the peaks were determined using Fityk software. FTIR spectra of the sample were recorded using FT-IR Spectrometer IRaffinity 1 (Shimadzu, Japan) M-T curves were recorded between 5K and $400 \mathrm{~K}$ using a Squid magnetometer (Quantum Design, USA) at an applied magnetic field of 100 Oe and 500 Oe. Hyperthermia studies of different concentrations of maghemite nanoparticles were carried out using a $4.2 \mathrm{~kW}$ Ambrell Easy Heat 8310 system (US) at a frequency of $316 \mathrm{kHz}$ and a magnetic field of $30.2 \mathrm{kAm}^{-1}$ for colloidal dispersions of $\gamma-\mathrm{Fe}_{2} \mathrm{O}_{3}$ nanoparticles at various concentration, viz.0.025, 0.050, 0.075 and $0.100 \mathrm{wt} \%$. The temperature of the magnetic fluid was recorded using a radio frequency immune fiber optic temperature sensor.

\section{Results}

\subsection{Structural characterization}

The X-ray diffraction pattern of the maghemite sample is given in Figure 2 (a). All the peaks of the XRD spectra are indexed by comparing them with JCPDS card no. 39-1340 for cubic $\gamma$ $\mathrm{Fe}_{2} \mathrm{O}_{3}$ structure. This shows the formation of a single phase maghemite phase. The crystalline nature of the low power sonochemically prepared maghemite is also visible from figure 2 (a). The refinement of the XRD data was performed using FullProf software. 

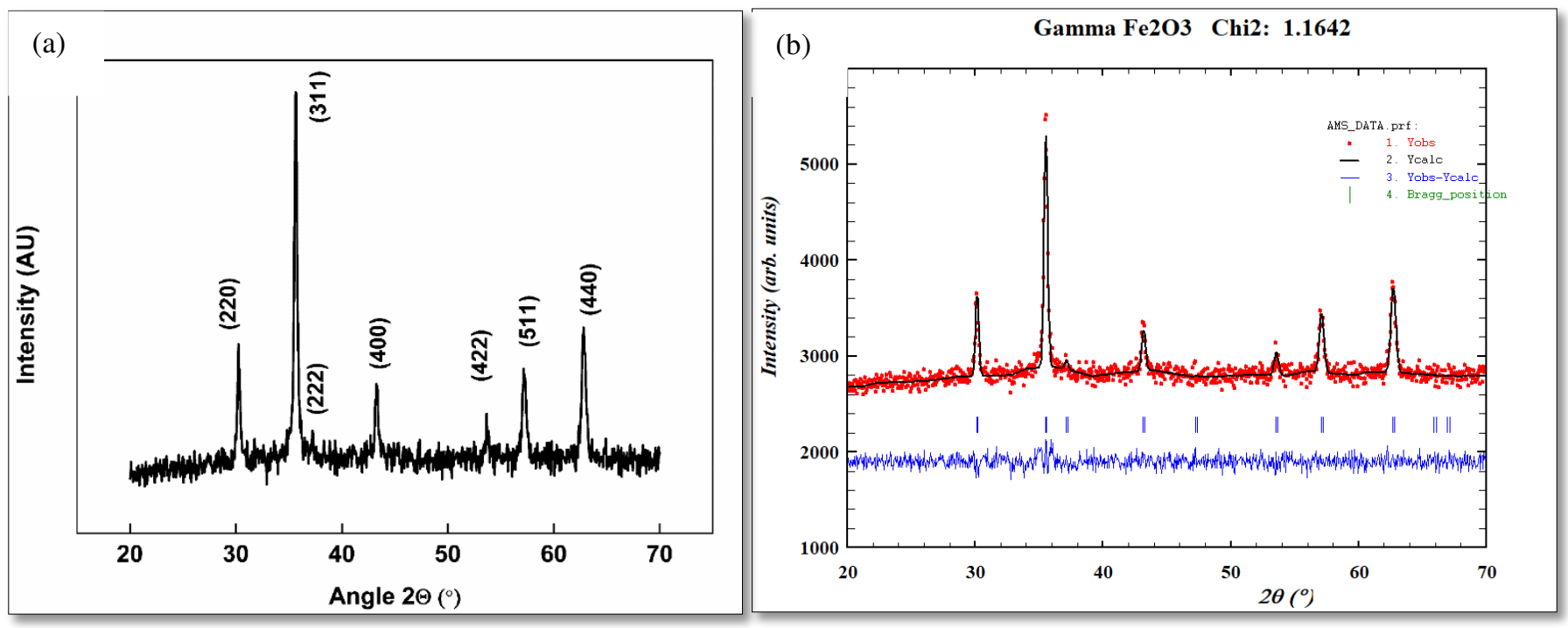

Figure 2: (a) XRD pattern of Maghemite sample and (b) Rietveld refinement of maghemite considering Fd3m space group

According to Pecharroman et al. [17], there is three possible space group for maghemite. One is the tetragonal one with space group, P4_32_12. Due to the tetragonal structure, $a=b$, and c=3a, peak splitting will be prominent here. The absence of peak splitting rules out the possibility of a tetragonal phase of maghemite. There are two space groups associated with cubic structure with similar values of the lattice parameter. They are Fd3m and P4_132. Among this, the space group P4-132 shows the XRD peak of relative intensity of $7 \%$ around $24^{\circ}$. However, our XRD pattern does not show the presence of a peak of around $24^{\circ}$. Thus Rietveld refinement was used as a tool to decide the space group of the material in addition to determining the lattice parameter. The refinement obtained is presented in Figure 2 (b). The observed pattern, calculated pattern, and the difference between the observed and calculated pattern is presented in Figure 2 (b). As can be seen from Figure 2 (b), good fitting was achieved for the maghemite sample. A global chi ${ }^{2}$ value of 1.40 and $\mathrm{a} \mathrm{Chi}^{2}$ value of 1.2 was obtained by the fitting. These values provide the figure of merit of the fitting. The lattice parameter obtained using Rietveld refinement is 8.3799(2) $\AA$ in contrast to the $8.33 \AA$ for bulk maghemite. 
In addition to it, peak broadening is visible in all the peaks in the sample. The full width at half maxima (FWHM) and the peak center position of these peaks were found using Fityk software and fitting the peaks to pseudovoigt shape. The obtained FWHM and peak centers are used to calculate the strain and crystallite size following the Williamson- Hall method. The Williamson- Hall plot obtained for the maghemite sample is given in Figure 3.

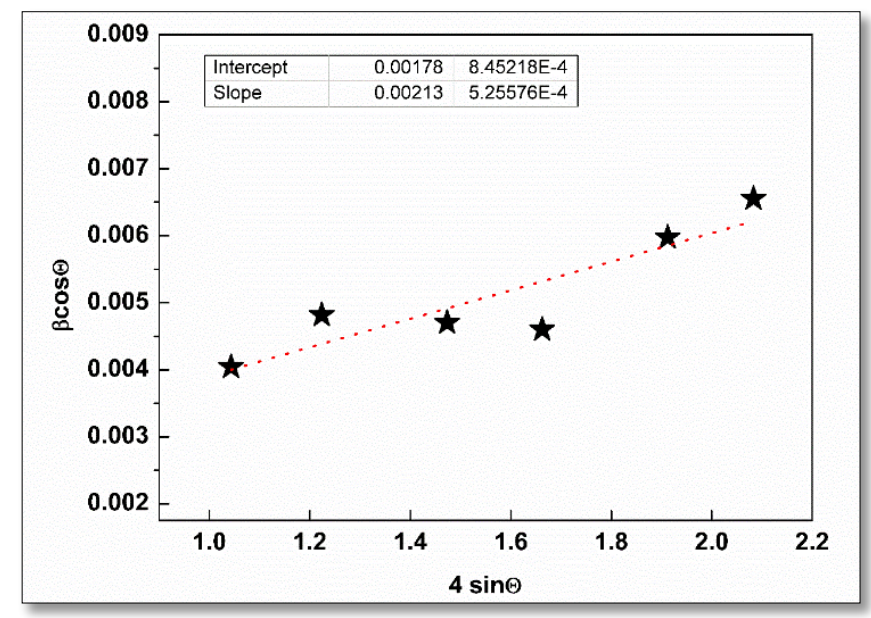

Figure 3: Williamson- Hall Plot of maghemite sample

From Figure 3 , the plot of $\beta \cos \theta$ vs $\sin \theta$ for all the peaks falls in a straight line. These points were fit to a straight line and the fitting is given by the dotted line. The slope of this line gives the strain in the material. As can be seen from Figure 3, the strain in the material is around 0.00213. In addition to it, the intercept of the line gives an estimate of the crystallite size as per the equation, $d=k \lambda / c$, where $\mathrm{k}$ is the shape factor, taken as 0.9 assuming spherical particles, $\lambda$ is the wavelength of the X-ray source and $\mathrm{c}$ is the intercept from Williamson-Hall plot. The calculated values of the crystallite size are around $77 \mathrm{~nm}$. 
The crystalline peaks visible from XRD shows that our low power sonochemical technique is yielding single-phase material without the need for high temperature. However, the presence of organics if any in the sample could not be understood by XRD measurement. Due to the lowtemperature methodology followed for the synthesis, the

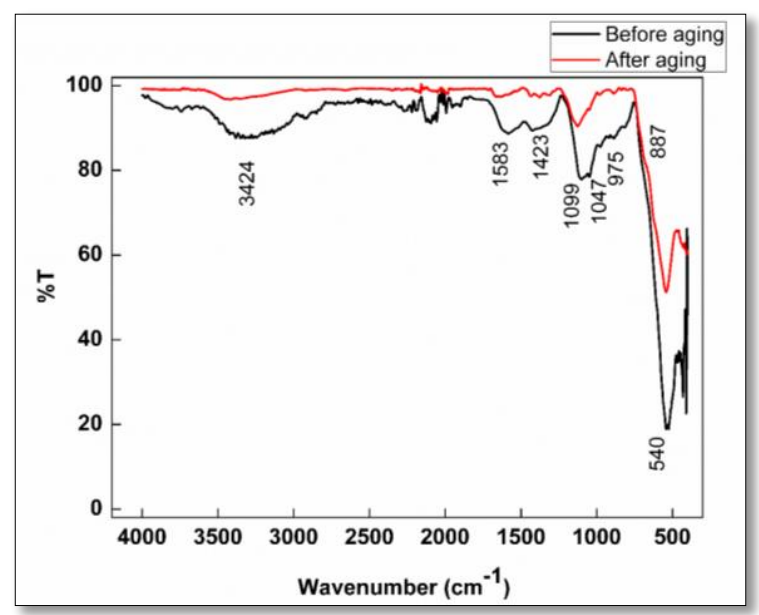

Figure 4: FTIR spectra of maghemite sample before and after aging samples were studied using FTIR spectroscopy. The FTIR spectra of the maghemite sample are given in Figure 4. As can be seen from Figure 4, the sample showed the presence of peaks of various vibrations. The peak around 3420 is attributed to $\mathrm{O}-\mathrm{H}$ stretching, around 1581 to $\mathrm{C}-\mathrm{H}$, 1420 to $\mathrm{O}-\mathrm{H}$ bending vibration, at 1100 , and 1050 to $\mathrm{C}-\mathrm{O}$ stretching. The vibrations around 540 are the signature peak of maghemite. The peaks, in general, could be attributed to water and alcohol content from the washing phase. To remove these organics, the sample was aged at room temperature for about 10 days. This was to ensure the natural removal of organics without the use of further thermal treatments. FTIR spectra of the sample after aging is also shown in Figure 4. As can be seen from Figure 4, the concentration of most of the organics has reduced. However, the presence of C-O stretching was still present with minor concentrations. This sample was used for further measurements. 


\subsection{Magnetic studies}

For understanding the magnetic properties of synthesized nanoparticles at room temperature and at elevated temperatures which are useful in hyperthermia studies, the magnetization of the maghemite $\left(\gamma-\mathrm{Fe}_{2} \mathrm{O}_{3}\right)$ sample was measured as a function of temperature at an applied magnetic field of 100 Oe and 500 Oe. This is given in Figure5 (a) and (b) respectively. From Figure5 (a) and (b), the zero-field cooled (ZFC) curve shows an increase in magnetization with temperature and remains saturated above $200 \mathrm{~K}$. Above this, the magnetization slightly decreases with an increase in temperature. In the case of the FC curve, magnetization decreases continuously with an increase in temperature. However, it is worth noting that both the FC and ZFC curves are not meeting even at a higher temperature of $400 \mathrm{~K}$ in the case of an applied field of 100 Oe. However, the onset of merging is evident in an applied field of 500 Oe. Blocking temperature, in this case, can be between 250 and 300K. Besides, a kink is visible in Figure 2 (a) at a temperature of around 30K. This kink is more apparent in Figure 2 (b) for an applied field of 500 Oe. This is attributed to the spin glass-like transition from a frozen spin state to an ordered ferrite magnetic spin. This also implies the presence of an amorphous shell-like structure on the surface of the formed particles [27]. Such a shell will be beneficial for hyperthermia applications to avoid agglomeration of the dispersed MNPs. From the M-T curve, a magnetization value around $34 \mathrm{emu} / \mathrm{g}$ is seen for the prepared sample. This shows that this sample can be used for hyperthermia studies at the applied field of nearly $500 \mathrm{Oe}$ in the temperature range 300 to $400 \mathrm{~K}$.
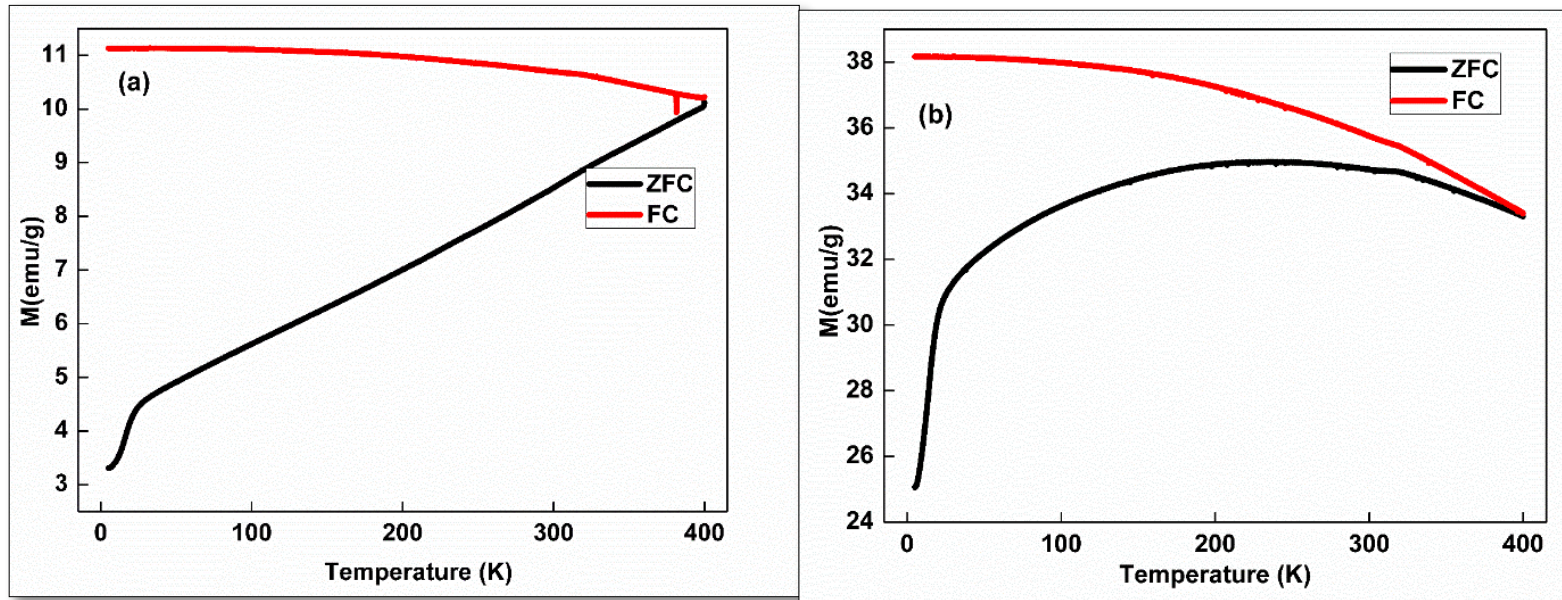

Figure 5: FC, ZFC measurement of maghemite at an applied field of (a) 100 Oe and (b) 500 Oe 


\subsection{Hyperthermia Studies}

Hyperthermia studies were carried out in the synthesized powder sample. Figure 6 gives the time-dependent calorimetric plot of iron oxide obtained by dispersing varying concentrations (from 0.025 to $0.100 \mathrm{wt} \%$ ) of maghemite nanoparticles in DI water. An appreciable increase in temperature from RT to about $46{ }^{\circ} \mathrm{C}$ which is desirable for Magnetic Hyperthermia therapy is observed in all samples. Samples with higher concentration exhibited effective hyperthermia response than lower concentration and the desired temperature was attained within less time (210 s). Table 1 gives the highest temperature achieved and time taken for it using iron oxide particles synthesized by various techniques.

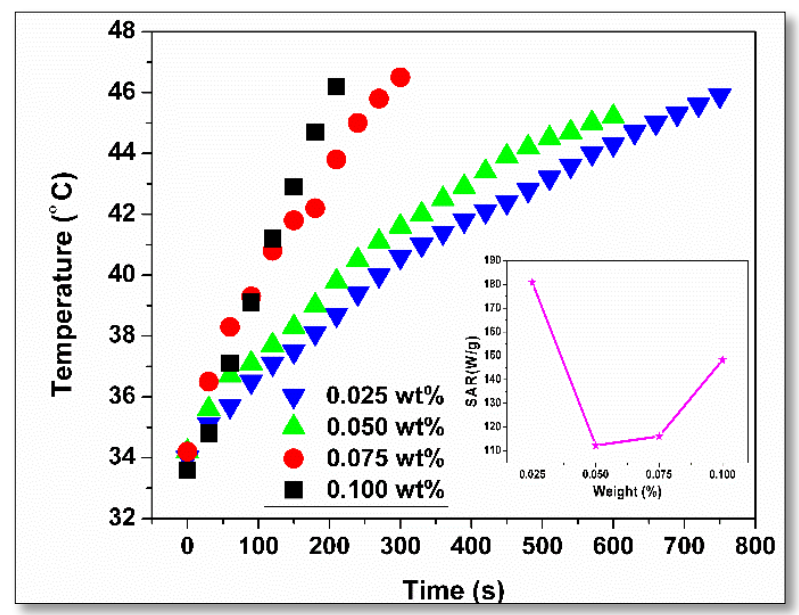

Figure 6: Hyperthermia studies carried out by varying $\gamma$-Fe2O3 concentration

From Table 1, it is evident that the concentration used by us is one of the lowest one among the various reported work. Besides, we have also achieved a higher temperature using the shortest possible time. $\gamma-\mathrm{Fe}_{2} \mathrm{O}_{3}$ nanoparticles synthesized by the sonochemical method showed a better time response and hence are compatible with hyperthermia treatment. The specific absorption rate was calculated from these using equation (1) [27]. This is given in the inset of Figure 6.

$$
S A R=C_{S} \frac{\Delta T}{\Delta t} \frac{M_{\text {water }}}{M_{F e 2 O 3}}
$$


Where SAR is the specific absorption rate, $\mathrm{C}_{\mathrm{s}}$ is the specific heat capacity of water $(4.187 \mathrm{~J} / \mathrm{g})$, $\Delta \mathrm{T} / \Delta \mathrm{t}$ is the slope of the calorimetric plot taken for 3.5 minutes in all cases.

From the inset, it is clear that the SAR values are more when the sample concentration is minimum. With further increase in sample concentration, the SAR value initially decreases and then shows a further increase wherein the SAR values slightly improves. Various SAR values reported in the literature are also shown in Table 1.Maximum SAR value obtained by us is 180 $\mathrm{W} / \mathrm{g}$ and is comparable with the reported value of $210 \mathrm{~W} / \mathrm{g}$ for $0.2 \mathrm{wt} \%$ [26].

Table.1. Comparison of reported values of increase in temperature with time for iron oxide particles synthesized by various techniques and their SAR values

\begin{tabular}{|c|c|c|c|c|c|c|c|}
\hline Conditions & Nanoparticle & $\begin{array}{l}\text { Synthesis } \\
\text { procedure }\end{array}$ & Amount & $\begin{array}{l}\text { Time } \\
(\mathrm{Sec})\end{array}$ & $\begin{array}{l}\text { Temperat } \\
\text { ure range }\end{array}$ & $\begin{array}{l}\text { SAR } \\
\text { value }\end{array}$ & Ref \\
\hline $\begin{array}{l}523 \mathrm{kHz}, \\
100 \mathrm{Oe}\end{array}$ & $\gamma-\mathrm{Fe}_{2} \mathrm{O}_{3}$ & Sol-gel method & $\begin{array}{c}20 \\
\mathrm{mg} / \mathrm{ml}\end{array}$ & $\begin{array}{l}500- \\
1500\end{array}$ & $40-50$ & $\begin{array}{c}12 \\
W / g\end{array}$ & 26 \\
\hline $\begin{array}{l}110 \mathrm{kHz} \\
100 \mathrm{Oe}\end{array}$ & $\gamma-\mathrm{Fe}_{2} \mathrm{O}_{3}$ & Sol-gel method & $\begin{array}{c}20 \\
\mathrm{mg} / \mathrm{ml}\end{array}$ & $\begin{array}{l}1000- \\
1500\end{array}$ & 35 & $6 \mathrm{~W} / \mathrm{g}$ & 26 \\
\hline $\begin{array}{l}523 \mathrm{kHz} \\
100 \mathrm{Oe}\end{array}$ & $\gamma-\mathrm{Fe}_{2} \mathrm{O}_{3}$ & Sol-gel method & --- & $\begin{array}{l}500- \\
2000\end{array}$ & $39-51$ & $\begin{array}{c}12 \\
\mathrm{~W} / \mathrm{g}\end{array}$ & 28 \\
\hline $\begin{array}{l}316 \mathrm{kHz} \\
377 \mathrm{Oe}\end{array}$ & $\mathrm{Fe}_{3} \mathrm{O}_{4}$ & $\begin{array}{l}\text { Hydrothermal } \\
\text { method }\end{array}$ & $1 \mathrm{mg} / \mathrm{ml}$ & $\begin{array}{l}300- \\
480\end{array}$ & $41-45$ & $\begin{array}{l}183 \\
\mathrm{~W} / \mathrm{g}\end{array}$ & 27 \\
\hline $\begin{array}{l}316 \mathrm{kHz} \\
377 \mathrm{Oe}\end{array}$ & $\mathrm{Fe}_{3} \mathrm{O}_{4}$ & $\begin{array}{l}\text { Hydrothermal } \\
\text { method }\end{array}$ & $2 \mathrm{mg} / \mathrm{ml}$ & $\begin{array}{l}100- \\
200\end{array}$ & $40-50$ & $\begin{array}{r}210 \\
W / g\end{array}$ & 27 \\
\hline $\begin{array}{l}265 \mathrm{kHz} \\
335.2 \mathrm{Oe}\end{array}$ & $\mathrm{Fe}_{3} \mathrm{O}_{4}$ & $\begin{array}{c}\text { Coprecipitation } \\
\text { method }\end{array}$ & --- & $\begin{array}{l}60- \\
300\end{array}$ & $43-58$ & $\begin{array}{l}118 \\
\mathrm{~W} / \mathrm{g}\end{array}$ & 1 \\
\hline
\end{tabular}




\begin{tabular}{|c|c|c|c|c|c|c|c|}
\hline $\begin{array}{l}362 \mathrm{kHz} \\
128 \mathrm{Oe}\end{array}$ & $\gamma-\mathrm{Fe}_{2} \mathrm{O}_{3}$ & $\begin{array}{c}\text { Coprecipitation } \\
\text { method }\end{array}$ & $\begin{array}{c}6.5 \\
\mathrm{mg} / \mathrm{ml}\end{array}$ & $\begin{array}{l}200- \\
360\end{array}$ & $40-48$ & --- & 15 \\
\hline $\begin{array}{l}252 \mathrm{kHz} \\
\sim 200 \mathrm{Oe}\end{array}$ & $\begin{array}{c}\mathrm{Fe}_{3} \mathrm{O}_{4} \\
\text { @ APTES }\end{array}$ & $\begin{array}{c}\text { Massart's } \\
\text { method }\end{array}$ & $5 \mathrm{mg} / \mathrm{ml}$ & 120 & $27-29$ & 67.2 & 29 \\
\hline $23-70 \mathrm{Oe}$ & $\mathrm{Fe}_{3} \mathrm{O}_{4}-\mathrm{PEG}$ & $\begin{array}{c}\text { Coprecipitation } \\
\text { method }\end{array}$ & $\begin{array}{l}5-40 \\
\mathrm{mg} / \mathrm{ml}\end{array}$ & 180 & $0-30$ & 10 & 30 \\
\hline $\begin{array}{l}316 \mathrm{kHz} \\
377 \mathrm{Oe}\end{array}$ & $\gamma-\mathrm{Fe}_{2} \mathrm{O}_{3}$ & Sonochemical & $1 \mathrm{mg} / \mathrm{ml}$ & $\begin{array}{l}120- \\
240\end{array}$ & $40-46.5$ & $\begin{array}{r}180 \\
\mathrm{~W} / \mathrm{g}\end{array}$ & $\begin{array}{l}\text { This } \\
\text { work }\end{array}$ \\
\hline
\end{tabular}

APTES- (3-aminopropyl)trimethoxysilane; PEG- polyethylene glycol

We could demonstrate higher magnetic hyperthermia properties using our maghemite particles synthesized by low power and easy sonochemical method.

\section{Conclusion}

We have synthesized $\gamma-\mathrm{Fe}_{2} \mathrm{O}_{3}$ nanocrystalline particles by a low power, low temperature sonochemical method utilizing an ultrasonic bath. The structure of the sample was analyzed by Xray diffraction and showed the presence of highly crystalline maghemite particles. The lattice parameter of the sample was found employing Rietveld refinement. Williamson-Hall approach was used to estimate the strain in the material and to estimate the crystallite size. The suitability of the sample for magnetic hyperthermia treatment was confirmed by $\mathrm{F}$ and ZFC, MT measurement. A blocking temperature above $250 \mathrm{~K}$ was obtained with an applied magnetic field of 500 Oe. The calorimetric measurement showed that the samples exhibited a rise in temperature from 34 to about $46^{\circ} \mathrm{C}$ in a very short time of about $210 \mathrm{~s}$. The specific absorption rate calculation showed that the values are comparable with literature at a much lower sample concentration. 


\section{Acknowledgments}

The authors thank Prof. N. Venkataramani, IIT Bombay, and Prof. Shiva Prasad, IITRAM, Ahmadabad for extending their support. The authors thank Central Facility IIT Bombay for the Squid facility. The authors thank the management of VIT for providing 'VIT SEED GRANT' for carrying out this research work.

\section{Declaration}

Authors declare no potential conflict of interest. No Human participants and/ or Animals were involved in this study. The dataset generated during this work will be made available from corresponding author on reasonable request. The first draft of the manuscript was prepared by 'Janeesh Geroge M'. Authors 'Janeesh George M.' and 'Meera V.' contributed equally is experimental design and performance. All authors have approved the manuscript.

\section{References}

1. Z. Hedayatnasab, F. Abnisa, W. M. A. W. Daud, Mater. Des. 123(2017) 174

2. A. Espinosa, R. Di Corato, J. Kolosnjaj-Tabi, P. Flaud, T. Pellegrino, C. Wilhelm, ACS Nano. 10(2) (2016) 2436

3. Palanisamy Sathyadevi, Wang Yun-Ming, Dalton Trans.26 (2019)

4. Das Pradip, Salvioni Lucia, Malatesta Manuela, VurroFederica, Mannucci Silvia, Gerosa Marco, Rizzuto Maria Antonietta, Tullio Chiara, Degrassi Anna, Colombo Miriam, Ferretti M Anna, Ponti Alessandro' Calderan Laura, Prosperi Davide, J. Colloid Interface Sci.579 (2020) 186

5. Patade R.Supriya, Andhare D. Deepali, Somvanshi B.Sandeep, Jadhav A. Swapnil, Khedkar V. Mangesh, K. M. Jadhav, Ceram. Int. (2020)

6. Antone J Angelo, Sun Zaicheng, Bao Yuping, Magnetochemistry.5 (2019) 45

7. M. W. Marashdeh, B. Ababneh, O. M. Lemine, Ahmed Alsadig, K. Omri, L. ElMir, A. Sulieman, EssamMattar, Results Phys. 15 (2019) 102651

8. Dadfar Mohammadali Seyed, Roemhild Karolin, Drude I.Natascha, Stillfried Saskiavon, Knüchel Ruth, Kiessling Fabian, Lammers Twan, Adv. Drug Deliv. Rev.138 ( 2019 ) 302 
9. A. Bahari, J Supercond Nov Magn. 30 (2017) 2165

10. H.Shokrollahi, J. MagnMagn Mater.426 (2017) 74

11. Liu, Y., Wang, Y., Zhang, XS. et al J Inorg Organomet Polym 32 (2022), 700-712

12. O. A.Noqta, A. A.Aziz, I. A.Usman ,M.Bououdina, J Supercond Nov Magn. 32 (2019) 779

13. Liu Shixiang, Yu Bing, Wang Song, Shen Youqing,Cong Hailin,Adv. Colloid Interface Sci.281 (2020) 102165

14. R.Hergt, R.Hiergeist, I.Hilger, W.Kaiser, Y.Lapatnikov, S. Margel, U.Richter, J. MagnMagn Mater. 270(3) (2004) 345

15. E. M.Múzquiz-Ramos, V.Guerrero-Chávez, B. I.Macías-Martínez, C. M. López-Badillo, L. A.García-Cerda,Ceram. Int.41(1) (2015) 397

16. T. L.Kline, Y-H Xu, Y.Jing, J-P Wang,J MagnMagn Mater.321(10)(2009) 1525.

17. S. Butulija, V. Spasojević, G. Branković, M. Prekajski Đorđević, T. Radulović, A. Zarubica, B. Matović,, Mater. Lett. 314 (2022) 131856

18. M. W. Marashdeh, B. Ababneh,O. M. Lemine, Ahmed Alsadig,K. Omri, L. ElMir, A. Sulieman,EssamMattar Results Phys. 15 (2019) 102651

19. T.Atsumi, B.Jeyadevan, Y.Sato, K.Tohji, J MagnMagn Mater.310(2) (2007) 2841

20. I. Nurdin, M. R.Johan, I. I. Yaacob, B. C. Ang, A. Andriyana,Mater. Res. Innov18(6) (2014) 200

21. Dolores Reyman, Raquel Serrano,Adianez Garcia-Leis, Ultrason. Sonochem.23 (2015) 391

22. Marcelo A. Gonçalo, Lodeiro Carlos, Capelo LuisJosé, Lorenzo Julia,Oliveira Elisabete, Mater. Sci. Eng. C. Mater. Biol. Appl.106 (2020) 110104

23. M.Abbas, M. Takahashi, C.Kim, J Nanopart Res.15 (2013) 1354

24. I.Ray, S.Chakraborty, A.Chowdhury, S.Majumdar, A.Prakash, R. Pyare, A.Sen, Sensor Actuat B-Chem.130(2) (2008) 882

25. S.Theerdhala, D. Alhat, S. Vitta, D.Bahadur, J. Nanosci.8(8)(2008) 4268

26. O. M.Lemine, K.Omri, M.Iglesias, V.Velasco, P.Crespo, P. de la Presa, A.Al-Hajry, J. Alloys Compd.607 (2014) 125

27. S. Arunima Rajan, Madhulika Sharma, Niroj Kumar Sahu, J Supercond Nov Magn. (2019)

28. O. M. Lemine, K.Omri, L.Mir El, V.Velasco, P. Crespo, P. de la Presa, A.Hajry, Mater Res SocSymp Proc.( 2015)17797

29. M. Ognjanović, D.M. Stanković, Ž.K. Jaćimović et al. , J. Alloys Compd.884 (2021) 161075 
30. A. Miklewska, R. Tymkiewicz, E. Kruglenko, M. Krajewski, J. Magn. Magn. Mater.550 (2022) 168918 